\title{
Gingival Paste Dosage Form
}

National Cancer Institute

\section{Source}

National Cancer Institute. Gingival Paste Dosage Form. NCI Thesaurus. Code C149541.

Semi-solid single-dose or multidose preparation consisting of a paste of solid particles

finely dispersed in a hydrophilic basis intended for ging ival use to obtain a local effect. 